\title{
Structure and properties of hard nanostructured coatings in Cr-B-N system
}

\author{
$\underline{\text { Ph.V. Kiryukhantsev-Korneev }}^{1}$, J.F. Pierson ${ }^{2}$, \\ J.P Bauer $^{2}$, E.A. Levashov ${ }^{1}$, D.V. Shtansky ${ }^{1}$ \\ ${ }^{1}$ Scientific-Educational Center of SHS, State Technological University \\ "Moscow Institute of Steel and Alloys", Leninsky pr. 4, Moscow 119049, Russia \\ ${ }^{2}$ Laboratoire de Science et Génie des Surfaces (UMR CNRS 7570), Ecole des Mines, \\ Parc de Saurupt, CS 14 234, F-54042 Nancy cedex, France \\ kiruhancev-korneev@yandex.ru
}

The $\mathrm{CrB}_{2}$ thin coatings are of interest because of their high hardness, wear- and corrosion resistance [1,2]. Incorporation of nitrogen in transition metal-boron systems $\left(\mathrm{TiB}_{2}, \mathrm{ZrB}_{2}\right.$ etc.) often leads to enhancing of chemical, mechanical and tribological characteristics $[3,4]$. The objective of the present study is the investigation of structure and properties of Cr-B-N coatings.

The $\mathrm{CrB}_{2}$ targets were synthesized from exothermal powder mixtures by means of selfpropagating high-temperature synthesis [5]. The Cr-B-N coatings were obtained using DC magnetron sputtering of $\mathrm{CrB}_{2}$ target in an argon atmosphere or in a gaseous mixtures $\mathrm{Ar}+\mathrm{N}_{2}$ (Table 1). The total pressure was maintained at $0.2 \mathrm{~Pa}$. The diameter of the targets was $12.5 \mathrm{~cm}$ and the distance from the target to substrate was $9 \mathrm{~cm}$. During deposition, the applied bias voltage was kept constant at $-250 \mathrm{~V}$ and the substrate temperature was controlled at $250-300^{\circ} \mathrm{C}$. Coatings were deposited on single crystal Si (100), Ni foil, and cemented carbide substrates for various times to obtain $1.0-2.5 \mu \mathrm{m}$ thick coatings.

The structure, phase, and chemical composition of coatings were studied by means of transmission and scanning electron microscopy (TEM and SEM), X-ray diffraction (XRD), X-ray photoelectron spectroscopy (XPS) and electron probe microanalysis (EPMA). To evaluate the oxidation resistance and thermal stability, the samples were annealed at 500,700 and $900^{\circ} \mathrm{C}$ in air for 1 hour. The elemental depth profiles for oxidized coatings were obtained by second ion massspectrometry (SIMS). Adhesion (critical load $\mathrm{Lc}_{2}$ ), hardness (H), Young's modulus (E) friction coefficient (f) and wear rate ( $\mathrm{Vw}$ ) were evaluated by means of scratch-tester, nanohardness tester, and pin-on-disk tribometer (CSM Instruments). The electrochemical tests of the Cr-B-N coatings were carried out in $5 \mathrm{~N} \mathrm{H}_{2} \mathrm{SO}_{4}$ using three-electrode cell and VoltaLab 50 potentiostat (Radiometr analytical).

Chemical composition of coatings obtained by EPMA is present in the Table 1 .

Table 1. Chemical composition and properties of Cr-B-N coatings

\begin{tabular}{|c|c|c|c|c|c|c|c|c|c|c|c|c|}
\hline \multirow{2}{*}{ No } & \multirow{2}{*}{$\% \mathrm{~N}_{2}$} & \multicolumn{3}{|c|}{ Concentration, at $\%$} & \multirow{2}{*}{$\begin{array}{c}\mathrm{H}, \\
\mathrm{GPa}\end{array}$} & \multirow{2}{*}{$\begin{array}{c}\mathrm{E}, \\
\mathrm{GPa}\end{array}$} & \multirow[t]{2}{*}{$\mathrm{H} / \mathrm{E}$} & \multirow{2}{*}{$\begin{array}{l}\mathrm{W}, \\
\%\end{array}$} & \multirow{2}{*}{$\begin{array}{c}\mathrm{Lc}_{2}, \\
\mathrm{~N}\end{array}$} & \multirow{2}{*}{$\mathrm{f}$} & \multirow{2}{*}{$\begin{array}{c}\mathrm{Vw}, \\
\mathrm{mm}^{3} \mathrm{~N}^{-1} \mathrm{~m}^{-1}\end{array}$} & \multirow{2}{*}{$\begin{array}{c}\mathrm{i}_{\mathrm{P}}, \\
\mathrm{mAcm}^{-2}\end{array}$} \\
\hline & & $\mathrm{Cr}$ & $\mathrm{B}$ & $\mathrm{N}$ & & & & & & & & \\
\hline 1 & 0 & 30.9 & 69.1 & 0 & 29 & 297 & 0.0976 & 59 & 45 & - & - & 2.61 \\
\hline 2 & 10 & 30.6 & 62.8 & 6.6 & 36 & 273 & 0.1319 & 72 & $>90$ & 0.79 & $6.9 \cdot 10^{-6}$ & 3.09 \\
\hline 3 & 15 & 30.1 & 57.2 & 12.7 & 23 & 220 & 0.1045 & 68 & 70 & 0.77 & $3.6 \cdot 10^{-6}$ & 0.59 \\
\hline 4 & 25 & 29.5 & 54.7 & 15.8 & 19 & 177 & 0.1073 & 68 & $>90$ & 0.76 & $3.9 \cdot 10^{-6}$ & 0.076 \\
\hline 5 & 85 & - & - & - & 15 & 151 & 0.0993 & 66 & - & 0.78 & $5.1 \cdot 10^{-6}$ & - \\
\hline
\end{tabular}

The nitrogen concentration in coatings increased from 0 to 15.8 at $\%$ when the nitrogen partial pressure was raised from 0 to $25 \%$. Note that $\mathrm{B} / \mathrm{Cr}$ ratio in coatings was equal to 2.2.-1.9 and did not significantly change with nitrogen partial pressure. Carbon and oxygen were also detected in an amount of 2.0-2.5 at \%. Their occurrence can be explained by the presence of impurities in the target and/or in the residual gas within the chamber. 
According to the $\mathrm{Cr} 2 \mathrm{p}$ and $\mathrm{B} 1 \mathrm{~s}$ XPS spectra, $\mathrm{CrB}_{2}$ was the main phase in non-reactive coating No. 1. In contrast, the $\mathrm{CrB}_{2}$ and $\mathrm{BN}$ phases were detected in all reactive deposited coatings Nos. 2-4. The volume fraction of $\mathrm{BN}$ phase increased with nitrogen concentration. Other phases, such as $\mathrm{CrB}, \mathrm{Cr}_{2} \mathrm{~B}, \mathrm{CrN}$ and $\mathrm{Cr}_{2} \mathrm{~N}[6,7]$ were not detected in the $\mathrm{Cr} 2 \mathrm{p}, \mathrm{B} 1 \mathrm{~s}$ and $\mathrm{N} 1 \mathrm{~s}$ spectra of Cr-B-N coatings Nos. 2-4.

The structural characterization using XRD and selected area electron diffraction patterns identified all the Cr-B-(N) coatings except No. 5 as having a hexagonal close-packed $\mathrm{AlB}_{2}$-type structure and no additional phases were detected (Fig. 1). The coatings deposited in Ar and at lowest nitrogen partial pressure of $10 \%$ were highly textured with (001) axis normal to the substrate surface. The (001) preferred orientation became less pronounced when nitrogen partial pressure was further raised. According to dark-field TEM images, the average crystallite size decreased from 15-17 nm for non-reactive coatings to 5 and $3 \mathrm{~nm}$ for the coatings deposited in gaseous mixtures of $\mathrm{Ar}+\mathrm{N}_{2}$ with $10 \%$ and $15-25 \%$ of nitrogen (Fig. 1). It may be result from $\mathrm{CrB}_{2}$-crystals growth interruption by thin amorphous layers, probably based on $\mathrm{BN}$. The morphology of coatings changed from dense-columnar (coatings No. 1) to the globular (Nos. 2-4) when the nitrogen was added in the working gas. The XRD spectra for coating No. 5 had two broad peaks with low intensity near position of cubic face-centered $\mathrm{CrN}$. The very fine crystallites of $\mathrm{CrN}$ phase, 1-1.5 $\mathrm{nm}$ in size, were embedded in the BN phase. The TEM data for the No. 5 are presented in Fig.1.
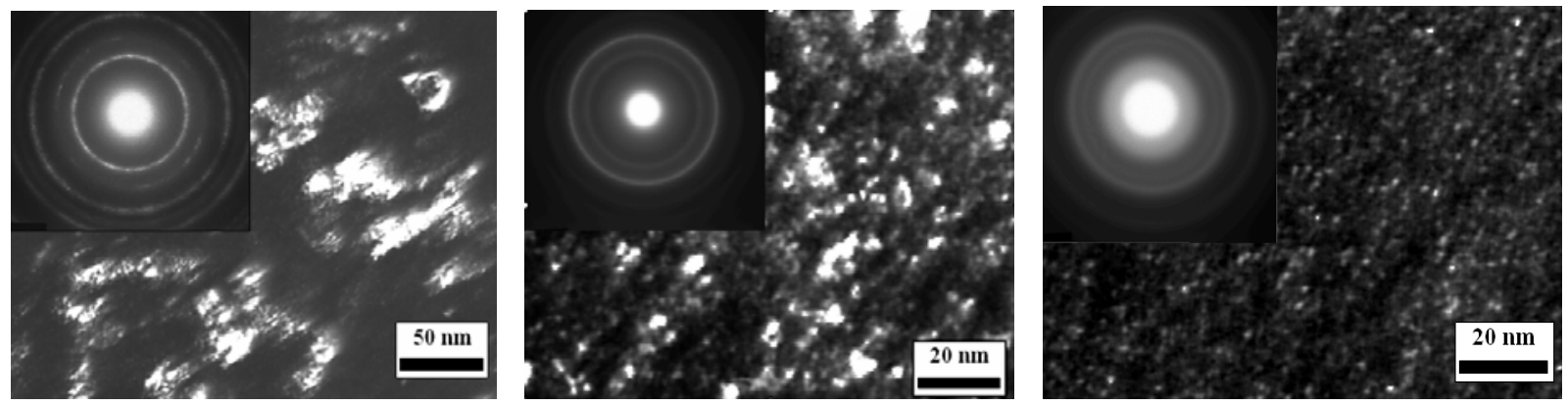

Fig. 1. Dark-field TEM-images and selected area electron diffraction patterns of coatings No. 1, No. 2, and No. 5 (from left to right).

The values of hardness, Young's modulus and elastic recovery are present in the Table 1. Coatings deposited on Si substrate were evaluated at the normal load of $4 \mathrm{mN}$. It can be seen that the hardness versus nitrogen concentration has an extreme character. The maximum value 36 GPa was obtained for coatings No. 3 with 6.6 at \% of nitrogen. When the nitrogen concentration was further raised, the hardness significantly decreased. The better mechanical properties of sample No. 3 may be attributed with maximal level of the compressive stress about 2.2 GPa. For other coatings the lower values in the range of 0.2-1.7 GPa were recorded. The combination of stoichiometric composition of crystalline $\mathrm{CrB}_{2}$ phase and optimal volume fraction of amorphous BN phase in the coating No. 3 can also positively affect the hardness $[8,9]$. Note that coating No.3 showed highest value of elastic recovery up to $72 \%$. The Young's modulus decreased from $\sim 300$ down to $\sim 180 \mathrm{GPa}$ when nitrogen concentration were raised from 0 to 15.8 at $\%$. It is a result of increasing of soft a-BN phase concentration in coatings.

The coating No. 1 showed a good adhesion to the cemented carbide substrate. The first delamination was observed at the load 45-50 N. The coatings Nos. 2-4 demonstrated resistance to failure up to $70-90 \mathrm{~N}$ and even higher. This difference may be related with higher elastic 
properties of Cr-B-N coatings (Table 1). Note that cracks at the borders of the scar were only observed in the coatings with low nitrogen concentration. Thus nitrogen alloying enhanced the fracture toughness of relatively brittle chromium diboride coatings.

The tribological tests were performed with normal load $5 \mathrm{~N}$ and linear speed $10 \mathrm{~cm} / \mathrm{s}$, using 3-mm 100Cr6 ball. The non-reactive coatings wore up to substrate at the first $10 \mathrm{~m}$ of distance because high fragility, whereas all coatings with nitrogen showed low wear rate within the range of $(3-7) \cdot 10^{-6} \mathrm{~mm}^{3} \mathrm{~N}^{-1} \mathrm{~m}^{-1}$. No correlation between hardness and wear resistance were observed. In contrast, the $\mathrm{H} / \mathrm{E}$ ratio $[10,11]$ can be used to predict tribological behavior (Table 1). The 3D images of the wear tracks are presented in Fig. 2. The friction coefficient of Cr-B-N coatings was within the range of 0.76-0.79 during the whole sliding distance of $130 \mathrm{~m}$.
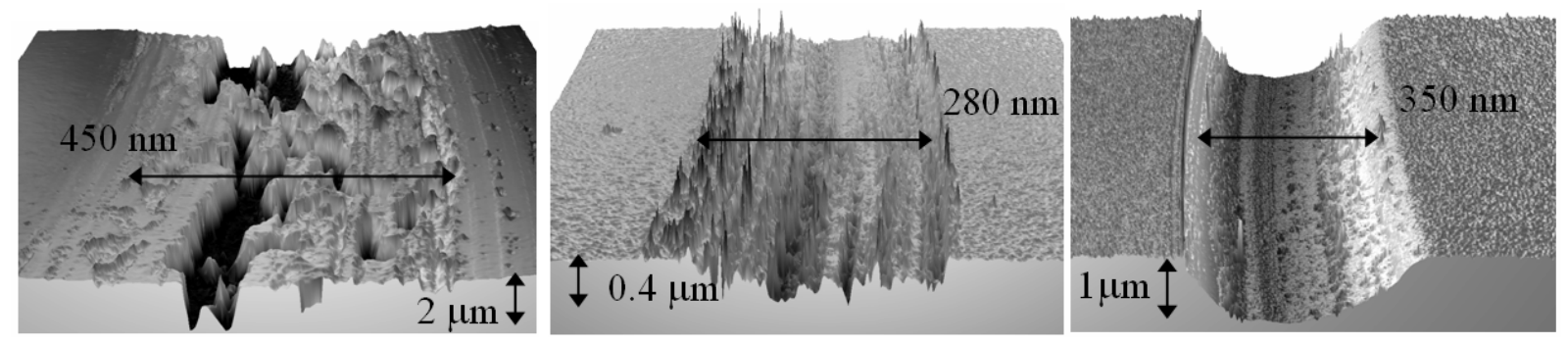

Fig. 2. The 3D images of the $2 \mu \mathrm{m}$ thick coatings No. 1, No. 2, and No. 5 (from left to right) after tribological tests

The oxidation depth for annealed coatings was obtained from SIMS element depth profiles. Because thickness of the oxide layers for $\mathrm{Cr}-\mathrm{B}$ and $\mathrm{Cr}-\mathrm{B}-\mathrm{N}$ coatings treated at $500^{\circ} \mathrm{C}$

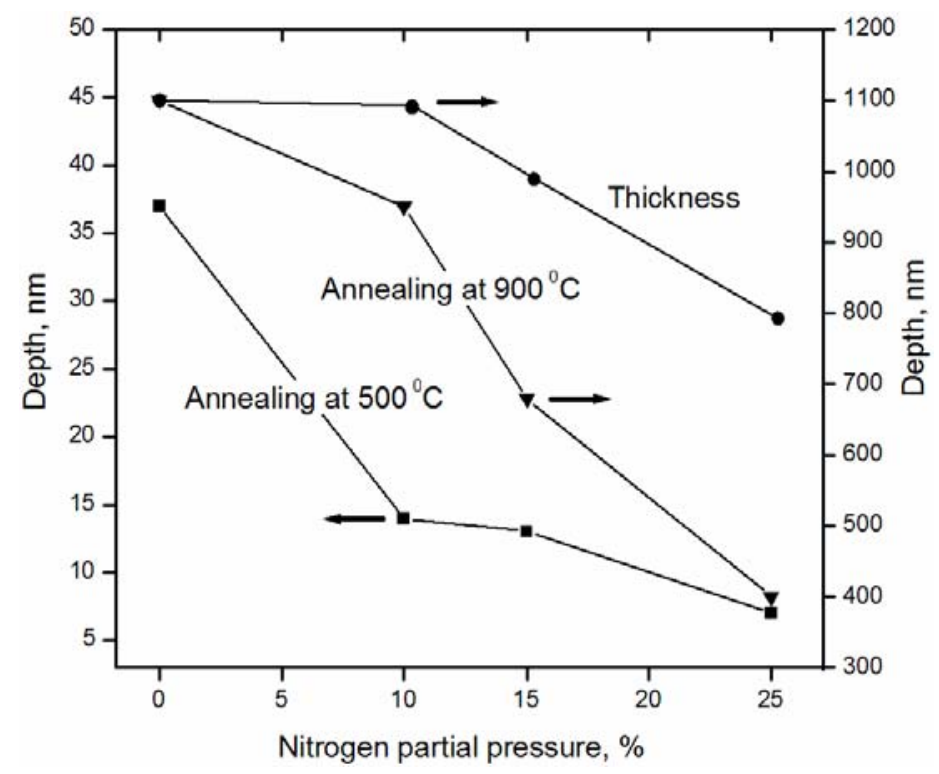

Fig. 3. The oxidation depth and coating thickness vs. nitrogen partial pressure was less than $50 \mathrm{~nm}$, second neutral mass-spectrometry was used to obtain the higher depth resolution. The dependence of the oxidation depth and coating thickness vs. nitrogen partial pressure, are shown on the Fig. 3. Oxidation rate of nitrogendoped coatings Nos. 2-4 at $500^{\circ} \mathrm{C}$ was $2.5-5$ times lower than that of $\mathrm{Cr}-\mathrm{B}$ coatings. The positive effect of nitrogen can be attributed to the formation of amorphous a-BN phase. It is known that diffusion of nonmetal atoms (oxygen) through the disordered areas is complicate to compare the crystalline structure $[12,13]$. Dense non-columnar structure with minimal volume of the voids can be responsible for high oxidation resistance. The $\mathrm{Cr}-\mathrm{B}$ coatings were completely 
oxidized after annealing at $900^{\circ} \mathrm{C}$, whereas coatings No. 2, No. 3, and No. 4 were partly oxidized with the oxidation depth of $86 \%, 68 \%$ and $50 \%$ of the coating thickness, respectively. The XRDspectra of the coatings Nos. 3-4 annealed at $700-900^{\circ} \mathrm{C}$ showed peaks from $\mathrm{CrB}_{2}$ and $\mathrm{Cr}_{3} \mathrm{O}$ phases. The formation of protective chromium oxide and chromium borate top-layers during heating can play important role for the enhancing of oxidation resistance of boronitride coatings $[14,15]$. Note that negative effect of nitrogen on the oxidation resistance of Cr-B-N coatings was reported [16].

The electrochemical tests were performed for the $\sim 1 \mu \mathrm{m}$ thick coatings deposited on the Si substrate. Prior to tests, samples were masked with a lacquer leaving $0.2 \mathrm{~cm}^{2}$ for interaction with the electrolyte. The free corrosion potentials were recorded after stabilization period for 1 hour. The $1 \mathrm{~N} \mathrm{H}_{2} \mathrm{SO}_{4}, 5 \mathrm{~N} \mathrm{H}_{2} \mathrm{SO}_{4}$ and $1 \mathrm{~N} \mathrm{HCl}$ solutions were used as environments. The maximal difference between coatings was obtained in $5 \mathrm{~N} \mathrm{H}_{2} \mathrm{SO}_{4}$. The results obtained show that nonreactive coatings and coatings Nos. 2 and 3 with low nitrogen content showed similar negative free corrosion potential $-230 \mathrm{mV}$. In contrast, coatings with 15.8 at $\%$ of nitrogen demonstrated positive value close to $250 \mathrm{mV}$. Potentiodynamic polarization measurements were performed over the electrode potential from -0.5 to $1.3 \mathrm{~V}$ with respect to the free corrosion potential with a scan rate of $1 \mathrm{mV} / \mathrm{s}$. The passivation current densities ( $\left.\mathrm{i}_{\mathrm{P}}\right)$ are listed in the Table 1 . All Cr-B-N coatings exclude No. 2 had higher corrosion resistance (lower values of $i_{\mathrm{P}}$ ) than Cr-B. The poor corrosion resistance of Cr-B-N coating No. 2 can be related with maximal level of compressive stresses in the coating.

The results obtained showed that the Cr-B-N coatings possess mechanical, tribological and anti-corrosion characteristics significantly higher than those of chromium diboride coatings. The advanced combination of properties makes Cr-B-N coatings promising candidate for protective coatings to be used in different environments.

The work was fulfilled due to financial support from EGIDE under grant 511500L. The work has been also supported in part by the Arcus project. We thank I.A. Bashkova, Dr. Yu. Pogozhev and A.E. Kutyrev for assistance with tribological and electrochemical tests.

1. K.L. Dahm, L.R. Jordan, J. Haase, P.A. Dearnley. Surf. Coat. Technol. 108-109 (1998) 413

2. M.Audronis, P.J. Kelly, R.D. Arnell, A. Leyland, A. Matthews. Surf. Coat. Technol. 200 (2005) 1366

3. H. Holzschuh. Thin Solid Films 469-470 (2004) 92

4. C. Heau, J.P. Terrat. Surf. Coat. Technol. 108-109 (1998) 332-339

5. E.A. Levashov, A.S. Rogachev, V.I. Ukhvid, I.P. Borovinskaya, Physico-chemical and technological bases of selfpropagating high-temperature synthesis. Moscow: Binom, 1999, p. 176

6. S.M. Aouadi, F. Namavar, E. Tobin, N. Finnegan, R.T. Haasch, R. Nilchiani, J.A. Turner, S.L. Rohde. J. Appl. Phys. 91 (2002) 1040

7. Y. Sakamaoto, M. Nose, T. Mae, E. Honbo, M. Zhou, K. Nogi. Surf. Coat. Technol. 174-175 (2003) 444

8. D.V. Shtansky, E.A. Levashov, A.N. Sheveiko, J.J. Moore. J. Mater. Synth. Process. 7 (1999) 187

9. S. Veprek, M. Haussmann, S. Reiprich, L. Shizhi, J. Dian. Surf. Coat. Technol. 86-87(1996) 394

10. I.V. Kragelsky. Friction and Wear 1 (1980) 12

11. A. Leyland, A. Matthews. Wear 246 (2000) 1

12. D.K. Belashchenko. Phys. Usp. 42 (1999) 297

13. N. Farkas, G. Zhang, K.M. Donnelly, E.A. Evans, R.D. Ramsier, J.A. Dagata. Thin Solid Films 447-448 (2004) 468

14. Ph.V. Kiryukhantsev-Korneev, D.V. Shtansky, M.I. Petrzhik, E.A. Levashov, B.N. Mavrin. Surface and Coatings Technology 201 (2007) 6143

15. D.V. Shtansky, Ph.V. Kiryukhantsev-Korneev, A.N. Sheveyko, A.E. Kutyrev, E.A. Levashov. Hard tribological Ti-Cr-B-N coatings with enhanced thermal stability, corrosion- and oxidation resistance. Surface and Coatings Technology, 2007 (in press)

16. M. Zhou, M. Nose, K. Nogi. Surface and Coatings Technology 183 (2004) 45 